\title{
Diversidade de Oomycota da Reserva Biológica de Paranapiacaba, Santo André, SP: primeiras citações para o Brasil $^{1}$
}

\author{
ALEXANDRA LENK GOMES ${ }^{2}$ e CARMEN LIDIA AMORIM PIRES-ZOTTARELLI ${ }^{2,3}$
}

(recebido: 18 de agosto de 2005; aceito: 14 de setembro de 2006)

\begin{abstract}
Oomycota diversity from the "Reserva Biológica de Paranapiacaba", Santo André, SP: first records for Brazil). To study the diversity of Oomycota from the "Reserva Biológica de Paranapiacaba", water and soil samples were collected, every three months, from November/2003 to November/2004 and baited with cellulosic and keratinous substrates. Of the 175 isolations, 35 species were identified, six of which are mentioned for the first time to Brazil descriptions, illustrations and comments are provided for them. One belongs to Leptolegniellaceae (Leptolegniella exogena Karling), one to Pythiaceae (Pythium helicandrum Drechsler) and four to Saprolegniaceae (Achlya treleaseana (Humphrey) Kauffman, Leptolegnia subterranea Coker \& Harvey, Saprolegnia blelhamensis (Dick) Mil'ko and S. terrestris Cookson ex Seymour).
\end{abstract}

Key words - Atlantic Rainforest, diversity, Oomycetes, "Reserva Biológica de Paranapiacaba"

RESUMO - (Diversidade de Oomycota da Reserva Biológica de Paranapiacaba, Santo André, SP: primeiras citações para o Brasil). Para o estudo da diversidade de Oomycota da Reserva Biológica de Paranapiacaba, amostras de água e solo foram coletadas trimestralmente, de novembro/2003 a novembro/2004 e iscadas com substratos celulósicos e queratinosos. De 175 isolamentos realizados, 35 espécies foram identificadas, sendo seis mencionadas pela primeira vez para o Brasil e, descritas, comentadas e ilustradas no presente trabalho. Destas, uma é pertencente a Leptolegniellaceae (Leptolegniella exogena Karling), uma a Pythiaceae (Pythium helicandrum Drechsler) e quatro a Saprolegniaceae (Achlya treleaseana (Humphrey) Kauffman, Leptolegnia subterranea Coker \& Harvey, Saprolegnia blelhamensis (Dick) Mil'ko e S. terrestris Cookson ex Seymour).

Palavras-chave - diversidade, Mata Atlântica, oomicetos, Reserva Biológica de Paranapiacaba

\section{Introdução}

Atualmente, o filo Oomycota está inserido no Reino Straminipila, com apenas uma classe, Oomycetes, constituída de 12 ordens, 27 famílias, 92 gêneros e 808 espécies (Kirk et al. 2001). Este filo possui representantes cosmopolitas, sendo encontrados em água doce ou marinha, e no solo. Podem ser sapróbios, importantes na degradação e ciclagem de nutrientes nos ecossistemas, ou parasitas de algas, peixes, crustáceos, plantas, fungos, mamíferos, inclusive do homem (Alexopoulos et al. 1996).

Em áreas de Mata Atlântica ainda são poucos os estudos realizados com este grupo de organismos (Milanez et al. 1994, Pires-Zottarelli 1999). Na Reserva Biológica de Paranapiacaba os estudos foram iniciados na década de 70 por Rogers et al. (1970) por meio de coletas esporádicas. Vários anos após, SchoenleinCrusius et al. (1992), Pires-Zottarelli et al. (1993) e

\footnotetext{
1. Parte da dissertação de mestrado da primeira autora, Programa de Pós-Graduação em Biodiversidade Vegetal e Meio Ambiente do Instituto de Botânica, SP.

2. Instituto de Botânica, Seção de Micologia e Liquenologia, Caixa Postal 4005, 01061-970 São Paulo, SP, Brasil.

3. Autor para correspondência: zottarelli@uol.com.br
}

Schoenlein-Crusius et al. (1999) verificaram a ocorrência de fungos na decomposição de folhas de Alchornea triplinervia (Spreng.) Muell. Arg., Ficus microcarpa L.f. e Quercus robur L., realizando também a quantificação e verificando o requerimento nutricional dos táxons isolados. Antunes et al. (1993) verificaram o efeito de queimada na micota da reserva e concluíram que nas áreas afetadas pelo fogo houve uma diminuição na diversidade.

Em continuidade aos estudos anteriores, Schoenlein-Crusius \& Milanez (1998) demonstraram a rica diversidade existente na reserva por meio do estudo da sucessão fúngica em folhas de Alchornea triplinervia, em ambiente terrestre e aquático.

Apesar de vários estudos terem sido realizados na reserva, conhecia-se apenas 13 táxons pertencentes à Oomycota, oito deles em nível específico. O presente trabalho contribui, de forma significativa, para o conhecimento da diversidade de oomicetos da reserva, de áreas de Mata Atlântica do Estado de São Paulo e do Brasil.

\section{Material e métodos}

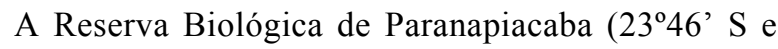
$46^{\circ} 18^{\prime}$ W), sob responsabilidade do Instituto de Botânica de São Paulo, está situada no Município de Santo André a 50 km 
da cidade de São Paulo, próxima ao complexo da Serra do Mar. A reserva possui 336 ha, estando a mesma bem preservada, levando-se em conta sua proximidade com o pólo industrial de Cubatão (Secretaria Estadual do Meio Ambiente 2000).

Para o estudo da diversidade dos oomicetos, foram realizadas amostragens trimestrais, de novembro de 2003 a novembro de 2004, totalizando cinco coletas. A técnica utilizada, descrita em Milanez (1989), consistiu em coletas de água e solo com subseqüente iscagem em laboratório, com substratos celulósicos e queratinosos (sementes de Sorghum sp., epiderme de cebola, ecdise de cobra e cabelo). Para obtenção de cultura pura, foram utilizados meios específicos, sendo $\mathrm{MP}_{5}$ para Saprolegniaceae e CMA com antibióticos (penicilina, estreptomicina, vancomicina), para Pythiaceae.

Devido às recentes alterações que continuam sendo realizadas na taxonomia dos organismos inclusos neste reino, adotou-se neste trabalho, a tradicional divisão das ordens contida em Alexopoulos et al. (1996) e das famílias em Dick (1973).

Os isolados foram identificados com auxílio de literatura específica e, os espécimes identificados, preservados em frascos "Wheaton" com água destilada esterilizada (Milanez 1989), pelo método de Castellani (Figueiredo \& Pimentel 1975) e/ou em lâminas semi-permanentes. Em seguida, foram incorporados aos acervos da Seção de Micologia e Liquenologia do Instituto de Botânica de São Paulo (SP e SPC).

\section{Resultados e Discussão}

De um total de 175 isolamentos realizados, 35 espécies foram identificadas, sendo 28 pertencentes à Saprolegniales, quatro à Peronosporales, duas à Rhipidiales e, uma à Lagenidiales (tabela 1). Seis espécies, mencionadas pela primeira vez para o Brasil, são aqui descritas, comentadas e ilustradas. Destas, uma é pertencente a Leptolegniellaceae (Leptolegniella exogena Karling), uma a Pythiaceae (Pythium helicandrum Drechsler) e quatro a Saprolegniaceae (Achlya treleaseana (Humphrey) Kauffman, Leptolegnia subterranea Coker \& Harvey, Saprolegnia blelhamensis (Dick) Mil'ko e S. terrestris Cookson ex Seymour).

Chave para os gêneros

1. Zoosporângios indiferenciados do micélio

Leptolegniella

1. Zoosporângios diferenciados do micélio

2. Zoosporângios com proliferação interna

Saprolegnia

2. Zoosporângios sem proliferação interna

3. Zoósporos formados dentro de uma vesícula evanescente

Pythium

3. Zoósporos formados dentro do zoosporângio

4. Zoósporos dispostos em uma única fileira dentro do zoosporângio

Leptolegnia

4. Zoósporos dispostos em várias fileiras dentro do zoosporângio Achlya

\section{Achlya C.G. Nees}

Talo monóico ou dióico. Hifas robustas ou delgadas. Zoosporângios fusiformes, naviculados, cilíndricos ou clavados; renovação simpodial, basipetalar ou cimosa. Zoósporos usualmente dimórficos; zoósporos primários providos de flagelos apicais, encistando-se no ápice dos zoosporângios, onde se agrupam; zoósporos secundários reniformes, lateralmente biflagelados. Em algumas espécies os zoosporângios secundários apresentam liberação aplanóide, dictióide ou traustotecóide. Gemas presentes ou ausentes, funcionando como zoosporângio. Oogônios laterais, terminais ou intercalares, pedúnculos de variados comprimentos ou sésseis, forma variável, mas predominantemente esféricos ou piriformes; parede oogonial com ou sem ornamentação, ou lisa a irregular internamente; com ou sem poros. Anterídios presentes ou ausentes; ramos anteridiais díclinos, monóclinos, andróginos, exíginos ou hipóginos; células anteridiais clavadas ou tubulares; às vezes septadas; atracação lateral, apical ou por projeções digitiformes; tubos de fertilização usualmente presentes, raramente persistentes. Oosferas geralmente maturando. Oósporos excêntricos, cêntricos ou subcêntricos, ocasionalmente abortivos, de um a vários por oogônio; germinação, quando presentes, formando tubo de germinação delgado originando um zoosporângio (Johnson 1956, Johnson et al. 2002).

Achlya treleaseana (Humphrey) Kauffman, Ann. Rept. Mich. Acad. Sci. 8:26. 1906.

Basiônimo: Saprolegnia treleaseana Humphrey, Trans. Amer. Phil. Soc. 17:111. 1893.

Figuras 1-2 
Tabela 1. Táxons de Oomycota isolados da Reserva Biológica de Paranapiacaba de novembro/2003 a novembro/2004. (A = água; $\mathrm{S}=$ solo; $\mathrm{F}=$ freqüência).

Table 1. Oomycota of the "Reserva Biológica de Paranapiacaba" isolated from November/2003 to November/2004. (A= water; $\mathrm{S}=$ soil; $\mathrm{F}=$ frequency).

Táxons Nov/2003 Fev/2004 Mai/2004 Ago/2004 Nov/2004 F\%

Reino Straminipila

Filo Oomycota

Saprolegniales

Saprolegniaceae

Achlya apiculata de Bary

A. bisexualis Coker \& A. Couch

A. cambrica (Trow) Johnson*

A. flagellata Coker

A. klebsiana Pieters*

A. orion Coker \& Couch

S 20

$\begin{array}{llll} & \mathrm{S} & \mathrm{A} & 40 \\ \mathrm{~S} & & & 20\end{array}$

$\begin{array}{lllll}\mathrm{A} / \mathrm{S} & \mathrm{A} / \mathrm{S} & \mathrm{A} & \mathrm{A} & 80\end{array}$

$\mathrm{A} / \mathrm{S} \quad \mathrm{A} \quad 20$

A. prolifera C.G. Nees*

A. radiosa Maurizio

A. subterranea Coker \& Braxton*

A. treleaseana (Humphrey) Kauffman***

Aphanomyces cladogamus Drechsler*

A. irregulare Scott*

A. stellatus de Bary*

Brevilegnia diclina Harvey*

B. linearis Coker \& Braxton ex Couch*

Dictyuchus pseudodictyon Coker \& Braxton*

Geolegnia inflata Coker \& Harvey*

Leptolegnia eccentrica Coker \& Matthews**

L. subterranea Coker \& Harvey***

Phragmosporangium uniseriatum Seymour***

Pythiopsis humphreyana Coker**

P. irregularis Seymour**

Saprolegnia blelhamensis (Dick) Mil'ko***

S. diclina Humphrey*

S. subterranea (Dissman) Seymour*

S. terrestris Cookson ex Seymour ***

Leptolegniellaceae

Leptolegniella exogena Karling***

L. keratinophila Huneycutt*

Lagenidiales

Olpidiopsidaceae

Olpidiopsis saprolegniae var. saprolegniae (Braun) A/S

A

$\mathrm{A} / \mathrm{S}$

S

S

A

$\mathrm{A} / \mathrm{S}$

$\mathrm{A} / \mathrm{S}$

$\mathrm{A} / \mathrm{S}$

A/S

$\mathrm{A} / \mathrm{S}$

$\mathrm{A} / \mathrm{S}$

$\mathrm{S}$

A

S

A/S

$\mathrm{S}$

A

$\mathrm{A} / \mathrm{S}$

$\mathrm{S}$

$\mathrm{A} / \mathrm{S}$

S

S

$\mathrm{A} / \mathrm{S}$

$\mathrm{A} / \mathrm{S}$

$\mathrm{A} / \mathrm{S}$

A/S

A/S

$\mathrm{A} / \mathrm{S}$

$\mathrm{S}$

S

$\mathrm{S}$

S

S

$\mathrm{S}$

A

A

A

S

$\mathrm{S}$

S

20

40

Cornu*

Peronosporales

Pythiaceae

Pythiogeton ramosum Minden*

Pythium helicandrum Drechsler***

P. torulosum Coker \& Patterson*

P. undulatum H.E. Petersen*

Rhipidiales

Rhipidiaceae

Rhipidium interruptum Cornu*

Sapromyces androgynus Thaxter*
A

A

20

S 60

20

S 60

Total

$\begin{array}{lll}16 & 13 & 17\end{array}$
A

A

17

*primeira citação para a Reserva; **primeira citação para o Estado de São Paulo; ***primeira citação para o Brasil.

*new record for "Reserva Biológica de Paranapiacaba"; **new record for SãoPaulo State; ***new record for Brazil. 
Colônia de uma semana com $2 \mathrm{~cm}$ diâm. em semente de sorgo. Gemas presentes. Zoosporângios e zoósporos não observados. Oogônios terminais e intercalares, dolioformes, 82,5-262,5 × 52,5-135 $\mu \mathrm{m}$; parede papilada, raramente lisa. Anterídios andróginos. Oosferas maturando. Oósporos 2 a 20 por oogônio, subcêntricos, esféricos, 25-37,5 $\mu \mathrm{m}$ diâm., e ovais, $25-30 \times 20-37,5 \mu \mathrm{m}$.

Material examinado: BRASIL. São Paulo: Santo André, Reserva Biológica de Paranapiacaba, $23^{\circ} 46^{\prime} 78^{\prime}$ " S e $46^{\circ} 18^{\prime} 55^{\prime}$ " W (ponto 1) e $23^{\circ} 46^{\prime} 52^{\prime \prime} \mathrm{S}$ e $46^{\circ} 18^{\prime} 77^{\prime \prime} \mathrm{W}$ (ponto 3), amostra de solo e frutos submersos (Malus sp. e Myrciaria sp.), 26-V-2004, A.L. Gomes (SPC1986).

As principais características da espécie são oogônios dolioformes com parede papilada, os quais prevalecem, oósporos subcêntricos e rara produção de zoosporângios, os últimos não verificados no espécime isolado.

As características dos espécimes estudados concordam com as descritas em Johnson (1956) e Johnson et al. (2002), entretanto, os últimos autores tratam a espécie como Achlya androgyna (Archer) Johnson \& Seymour, como uma combinação nova. Maiores estudos sobre esta espécie devem ser realizados visando à resolução dos problemas taxonômicos. Na verdade, somente por meio de técnicas moleculares os problemas relatados pelos últimos autores poderão ser esclarecidos, enquanto isto, optou-se neste trabalho, pela classificação contida em Johnson (1956).

Distribuição mundial: Brasil, Estados Unidos, Inglaterra, Islândia, Nigéria e Nova Zelândia.

\section{Leptolegnia de Bary}

Talo monóico. Hifas longas, delicadas e ramificadas. Zoosporângios longos, filamentosos, cilíndricos, do mesmo tamanho que a hifa, ocasionalmente ramificados. Zoósporos dimórficos, dispostos em uma única fileira no zoosporângio; alongados durante a liberação, mas se tornando piriformes e nadando antes de encistar. Gemas ausentes. Oogônios laterais, esféricos a subesféricos, dolioformes; parede oogonial lisa ou ornamentada, sem poros. Pedúnculos oogoniais podendo ou não ser ramificados; espessura variada. Anterídios, quando presentes, andróginos, monóclinos ou díclinos; células anteridiais simples, atracação lateral ou apical. Oósporos excêntricos e subexcêntricos; 1 por oogônio, podendo preencher o oogônio (Coker \& Matthews 1937, Johnson et al. 2002).
Leptolegnia subterranea Coker \& Harvey in Harvey, J. Elisha Mitchell Sci. Soc. 41:158. 1925.

Figuras 3-6

Colônia de duas semanas com $2 \mathrm{~cm}$ diâm. em semente de sorgo. Gemas ausentes. Zoosporângios filiformes, 325-575 × 12,5-22,5 $\mu \mathrm{m}$; renovação cimosa. Liberação leptolegnióide; zoósporos encistados 10-15 $\mu \mathrm{m}$, dispostos em uma única fileira no zoosporângio. Oogônios laterais, terminais, intercalares, esféricos, 37,5-42,5 $\mu \mathrm{m}$ diâm., obovados, 35-50 × 27,5-42,5 $\mu \mathrm{m}$, dolioformes, 37,5-95 × 30-42,5 $\mu \mathrm{m}$; parede oogonial com papilas de 5,0-10 $\mu \mathrm{m}$ compr., algumas vezes lisa. Anterídios ausentes. Oosferas maturando. Oósporos 1 por oogônio, subexcêntricos, ovais, 27,5-87,5 $\times$ 22,5-35 $\mu \mathrm{m}$, esféricos, $25 \mu \mathrm{m}$ diâm.

Material examinado: BRASIL. São PAULo: Santo André, Reserva Biológica de Paranapiacaba,

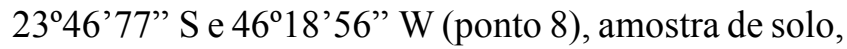
26-V-2004, A.L. Gomes (SPC1990).

As características principais da espécie são oósporos subexcêntricos, oogônios de parede lisa e papilada e anterídios ausentes. A variação na quantidade de papilas nos oogônios é bastante evidente, com a presença de oogônios lisos a densamente papilados, sendo a maioria intercalar, com um único oósporo preenchendo todo o oogônio.

O isolado apresentou zoosporângios e oogônios menores que os descritos por Harvey (1925) e Johnson et al. (2002). O primeiro autor cita zoosporângios de $785 \times 11,8 \mu \mathrm{m}$ e oogônios de 40-51,7 $\mu \mathrm{m}$ e, Johnson et al. (2002) zoosporângios de 200-985 × 9-12 $\mu \mathrm{m}$ e oogônios de 20-57 $\mu \mathrm{m}$.

Distribuição mundial: Brasil, Estados Unidos, Islândia, Japão, Noruega e Oceania.

\section{Leptolegniella Huneycutt}

Micélio intra e extramatrical; hifas irregulares, ocasionalmente septadas. Rizóides delgados e ramificados. Zoosporângios ramificados, indiferenciados do micélio vegetativo. Zoósporos emergindo incompletamente formados, diplanéticos. Estruturas de resistência formadas dentro da hifa e envoltas por porções do protoplasma, formadas assexuadamente. Sapróbio em substrato queratinoso (Sparrow 1960).

Leptolegniella exogena Karling, Nova Hedwigia 45(3/4):433. 1987.

Figuras 7-8

Micélio intra e extramatrical, constrito em intervalos, em ecdise de cobra. Hifas de 15-22,5 $\mu \mathrm{m}$ diâm., 

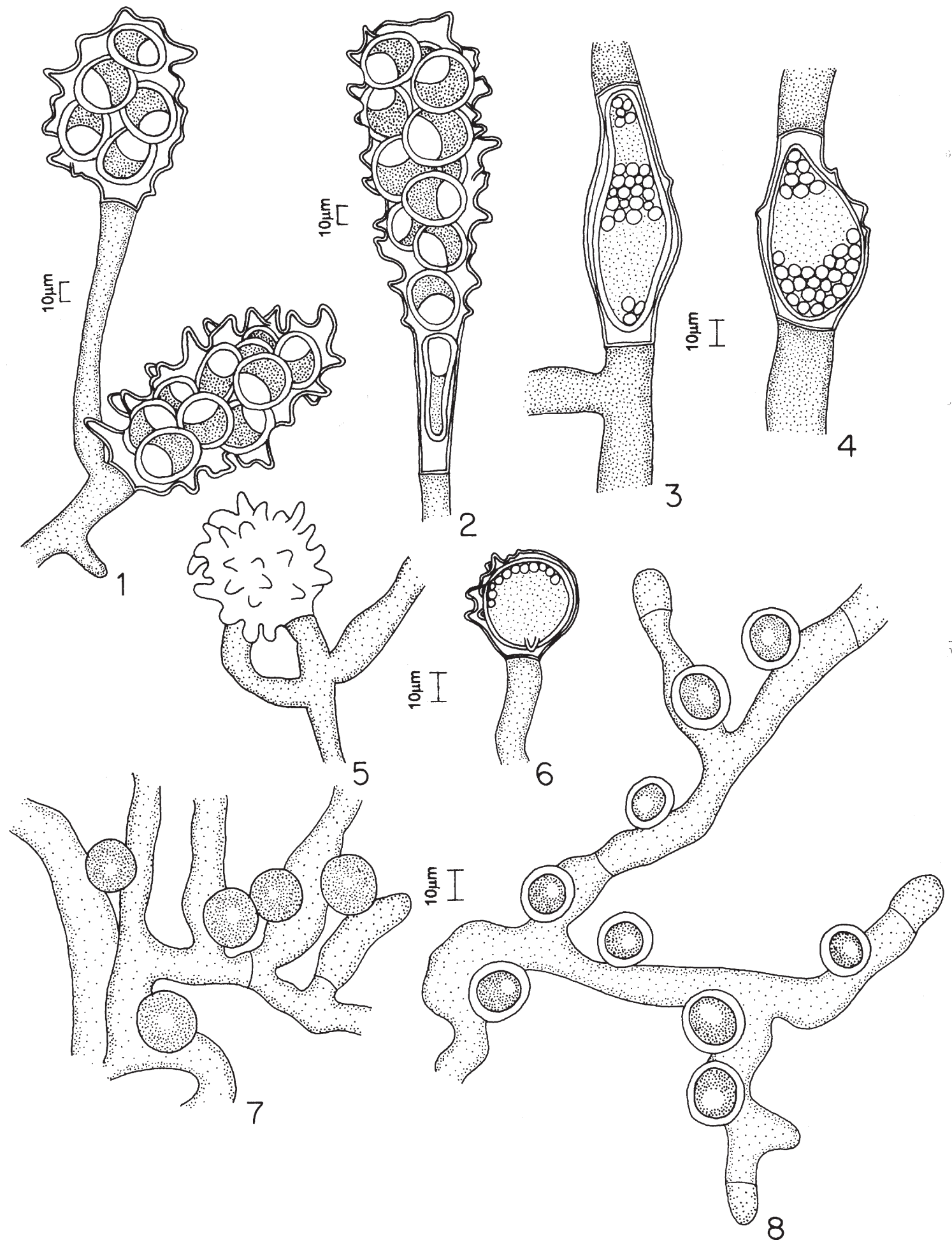

Figuras 1-8. Estruturas assexuais e sexuais. 1-2. Achlya treleaseana (Humphrey) Kauffman. Oogônios ornamentados e oósporos excêntricos. 3-6. Leptolegnia subterranea Coker \& Harvey. 3-4. Oogônios intercalares com papilas e oósporos subexcêntricos preenchendo todo o oogônio. 5. Oogônio vazio ornamentado. 6. Oogônio papilado e oósporo subexcêntrico. 7-8. Leptolegniella exogena Karling. 7. Processo de maturação dos esporos de resistência. 8. Esporos de resistência exógenos.

Figures 1-8. Asexual and sexual structures. 1-2. Achlya treleaseana (Humphrey) Kauffman. 1-2. Ornamented oogonia and eccentric oospores. 3-6. Leptolegnia subterranea Coker \& Harvey. 3-4. Intercalary oogonia with papillae and subeccentric oospores filling the oogonium. 5. Empty ornamented oogonia. 6. Papillated oogonia and subeccentric oospore. 7-8. Leptolegniella exogena Karling. 7. Maturation of the resting spores. 8. Exogenous resting spores. 
formando uma rede em todo substrato. Zoosporângios não diferenciados. Zoósporos esféricos, 10-12,5 $\mu \mathrm{m}$, emergindo para fora da hifa para formação dos esporos de resistência. Esporos de resistência esféricos, exógenos, $15-20 \mu \mathrm{m}$ diâm.

Material examinado: BRASIL. São PaUlo: Santo André, Reserva Biológica de Paranapiacaba, $23^{\circ} 46^{\prime} 53^{\prime \prime} \mathrm{S}$ e 4618'75" W (ponto 6), amostra de solo, 26-V-2004, A.L. Gomes (SP381315).

O processo de maturação dos esporos de resistência tem início com o protoplasma emergindo para fora da hifa, sendo que o restante da maturação acontece com o esporo totalmente fora, preso à superfície da hifa, sendo esta a característica principal da espécie. Foi isolada pela primeira vez da Tailândia e, reisolada de ecdise de cobra, asa de cupim e milho por Karling (1987) de amostras de solo do Panamá e Indiana (EUA).

$\mathrm{O}$ isolado estudado apresentou hifas e zoósporos um pouco maiores que os descritos por Karling (1987), que cita hifas de $8-20 \mu \mathrm{m}$ e zoósporos de 5-8 $\mu \mathrm{m}$, entretanto, os esporos de resistência estão de acordo com a descrição do autor.

Por não apresentar crescimento em meio de cultura, o espécime foi preservado em lâmina semi-permanente e, incorporado ao Herbário do Instituto de Botânica de São Paulo.

Distribuição mundial: Brasil, Estados Unidos, Panamá e Tailândia.

\section{Pythium Pringsheim}

Micélio bem desenvolvido, às vezes com apressórios, raramente com clamidósporos. Zoosporângios filamentosos, não diferenciados da hifa vegetativa, consistindo de elementos lobados ou torulóides inflados, ou com estruturas globosas ou subglobosas, às vezes com proliferação interna. Zoosporângios terminais, intercalares ou lateralmente sésseis, formando um tubo de descarga com variação em espessura e formando vesícula no ápice, na qual ocorre a diferenciação dos zoósporos biflagelados. Oogônios globosos ou subglobosos, esféricos ou elipsoidais, terminais ou intercalares, lisos ou ornamentados. Anterídios ausentes ou vários por oogônio, monóclinos, díclinos ou hipóginos, pedunculados ou sésseis, de várias formas. Oósporos usualmente 1 por oogônio, raramente de 2-4, plerótico ou aplerótico com parede fina ou espessa (Sparrow 1960, van der Plaats-Niterink 1981).

Pythium helicandrum Drechsler, Bull. Torrey Bot. Club 77(6):455. 1950.

Figuras 9-11
Zoosporângios elipsoidais, terminais, intercalares, 21-36 × 12-18 $\mu \mathrm{m}$. Zoósporos encistados $12 \mu \mathrm{m}$. Oogônios laterais, esféricos, 21-25,5 $\mu \mathrm{m}$; parede oogonial com ornamentações espinhosas de 1,5-3,0 $\mu \mathrm{m}$ compr. Anterídios díclinos, enrolando no pedúnculo do oogônio, 1 por oogônio; atracação lateral. Oósporos esféricos, 9-18 $\mu \mathrm{m}$, pleróticos.

Material examinado: BRASIL. São PAulo: Santo André, Reserva Biológica de Paranapiacaba, $23^{\circ} 46^{\prime} 52^{\prime \prime} \mathrm{S}$ e $46^{\circ} 18^{\prime} 77^{\prime}$ ' W (ponto 4) e $23^{\circ} 46^{\prime} 53^{\prime \prime} \mathrm{S}$ e $46^{\circ} 18^{\prime} 69^{\prime \prime} \mathrm{W}$ (ponto 7), amostras de solo, 20-XI-2003, 26-II-2004, 18-XI-2004, A.L. Gomes (SPC1959).

As características principais da espécie são oogônios com ornamentações espinhosas e ramos anteridiais enrolando no pedúnculo oogonial.

A descrição do espécime está de acordo com a de Drechsler (1950) e van der Plaats-Niterink (1981). Segundo a última autora, o espécime é normalmente encontrado como sapróbio em raízes de plantas em decomposição.

Distribuição mundial: Brasil, Estados Unidos e Holanda.

\section{Saprolegnia C. G. Nees}

Talo monóico. Hifa robusta ou delicada, ramificada ou não, reta ou flexuosa, afilando gradualmente da base para o ápice. Gemas presentes ou ausentes. Zoosporângios fusiformes, cilíndricos, clavados ou irregulares; renovação por proliferação interna; desenvolvimento simpodial ou basipetalar e ramificações cimosas. Zoósporos dimórficos; zoósporos primários usualmente piriformes com dois flagelos subapicais, nadando para longe do orifício zoosporangial após a descarga, encistando em seguida; cistos primários formando, na germinação, zoósporos secundários, reniformes e com flagelos laterais; cistos secundários germinando por uma hifa delgada ou zoósporos secundários, poliplanéticos; em algumas espécies e em culturas mais velhas descarga aplanóide ou dictióide presente. Oogônios laterais, terminais, intercalares ou sésseis; formas variáveis, predominando esféricos ou piriformes; parede oogonial geralmente com ou sem ornamentações; com ou sem poros. Anterídios geralmente presentes; ramos anteridiais diclinos, monoclinos, andróginos ou hipóginos; células anteridiais predominantemente tubulares ou clavadas, laterais; atracação apical ou por projeções digitiformes; tubos de fertilização freqüentemente presentes. Oosferas geralmente maturando. Oósporos um a vários, cêntricos, subcêntricos, subexcêntricos ou excêntricos, esféricos ou elipsóides, tamanho variável (Seymour 1970, Johnson et al. 2002). 
Saprolegnia blelhamensis (Dick) Mil'ko, Mikol. i Fitopatol. 13:290. 1979.

Basiônimo: Scoliolegnia blelhamensis Dick, Bot. J. Linn. Soc. 62:259. 1969.

Figuras 12-15

Colônia de duas semanas com 2,5 cm diâm. em semente de sorgo. Gemas presentes, irregulares. Zoosporângios filiformes, 62,5-250 × 20-27,5 ㅆm, com proliferação interna. Liberação saprolegnióide; zoósporos esféricos. Oogônios esféricos, 47,5-65 $\mu \mathrm{m}$ diâm., dolioformes, 42,5-102,5 × 45-47,5 $\mu \mathrm{m}$; parede com papilas de 3,75-12,5 $\mu \mathrm{m}$ compr., pedúnculo simples. Anterídios ausentes. Oosferas maturando. Oósporos 1 a 9 por oogônio, subcêntricos e subexcêntricos, esféricos, 22,5-30 $\mu \mathrm{m}$ e alongados, 27,5-32,5 $\times$ 20-22,5 $\mu \mathrm{m}$.

Material examinado: BRASIL. São PAUlo: Santo André, Reserva Biológica de Paranapiacaba, 2346'52" S e 46 $18^{\circ} 77^{\prime}$ " W (ponto 4), amostra de solo, 26-V-2004, A.L. Gomes (SPC1991).

As principais características da espécie são oósporos subcêntricos e subexcêntricos e ausência de anterídio. Dick (1969) considerou a espécie pertencente ao gênero Scoliolegnia, e classificou a estrutura dos oosporos como subexcêntrica. Já Seymour (1970), os classificou como subcêntricos tipo I e tipo II dentro do gênero Saprolegnia. O isolado apresentou diferentes tipos de organização lipídica nos oósporos, tornando esta uma característica importante para ser analisada.

As características principais do isolado estão de acordo com as descritas por Dick (1969) e Johnson et al. (2002). Os oogônios, maioria intercalares, apresentaram variações na quantidade de papilas na parede. Em alguns casos, pôde-se observar o espessamento do pedúnculo, devido à proximidade com o oogônio. Os zoosporângios formaram-se, em grande quantidade, apenas nas colônias jovens. Segundo Dick (1969), a espécie pode ser encontrada normalmente em brejos e águas com baixo pH e alta concentração de matéria orgânica.

Distribuição mundial: Brasil, Inglaterra e Noruega.

Saprolegnia terrestris Cookson ex Seymour, Nova Hedwigia (Beiheft) 19:37. 1970.

Figuras 16-19

Colônia com $1 \mathrm{~cm}$ diâm. em semente de sorgo. Gemas presentes. Zoosporângios filiformes, fusiformes, $(112,5-) 255-337,5(-400) \times 12,5-35 \mu \mathrm{m}$; renovação por proliferação interna. Zoósporos encistados,
(7,5-)10-12,5 $\mu \mathrm{m}$. Oogônios laterais e terminais, esféricos, (35-)42,5-67,5(-77,5) $\mu \mathrm{m}$ diâm., piriformes, 42,5-100 $\times 45-100 \mu \mathrm{m}$, parede oogonial lisa, poros na parede, pedúnculo simples. Anterídios andróginos e monóclinos, 1-2 por oogônio, células anteridiais simples, ramo anteridial dividido, atracação lateral e apical. Oosferas maturando. Oósporos 1 a 7 por oogônio, subcêntricos, esféricos, 25-37,5 $\mu \mathrm{m}$ diâm.

Material examinado: BRASIL. São PAULO: Santo André, Reserva Biológica de Paranapiacaba,

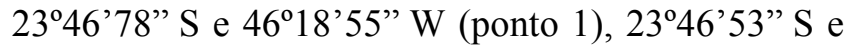

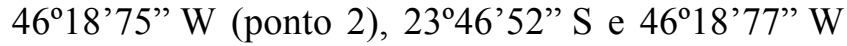

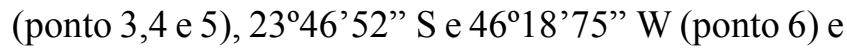
$23^{\circ} 46^{\prime} 53^{\prime \prime} \mathrm{S} 46^{\circ} 18^{\prime} 69^{\prime \prime} \mathrm{W}$ (ponto 7), amostras de água e solo, 20-XI-2003, 26-II-2004, 26-V-2004, 26-VIII-2004, A.L. Gomes (SPC1968).

As principais características da espécie são oósporos subcêntricos, com distribuição delicada das gotículas lipídicas e, anterídios, na maioria das vezes, andróginos. Cookson (1937) descreveu os oósporos como excêntricos levando em consideração o fato de haver gotas lipídicas maiores de um lado do oósporo. Seymour (1970) validou a espécie já que não havia diagnose latina. Nesta descrição, o autor alterou a classificação dos oósporos para subcêntricos e, em seus comentários, explica a variação dos oósporos em tipo I e II, característica não observada por I. Cookson.

As características dos isolados estudados estão de acordo com as descritas por Cookson (1937), Seymour (1970) e Johnson et al. (2002).

A espécie foi isolada pela primeira vez por Cookson (1937), de amostra de solo rica em húmus de Melbourne, Austrália.

Distribuição mundial: Austrália, Brasil, Canadá, China, Estados Unidos, Índia, Inglaterra, Iraque, Islândia, Iugoslávia, Japão, Nepal, Noruega, Nova Zelândia e Polônia.

O levantamento realizado na Reserva Biológica de Paranapiacaba contribuiu para a ampliação do conhecimento da diversidade de Oomycota no Brasil, sendo $20 \%$ das espécies identificadas primeiras citações para o Brasil, 9\% para o Estado de São Paulo e, 60\% para a Reserva. O restante das espécies, que somam $11 \%$, já possuíam relatos anteriores.

Agradecimentos - Ao CNPq pela bolsa concedida, à Fapesp pelo auxílio financeiro concedido ao projeto, e ao Instituto de Botânica de São Paulo pela infra-estrutura para o desenvolvimento do mesmo. 

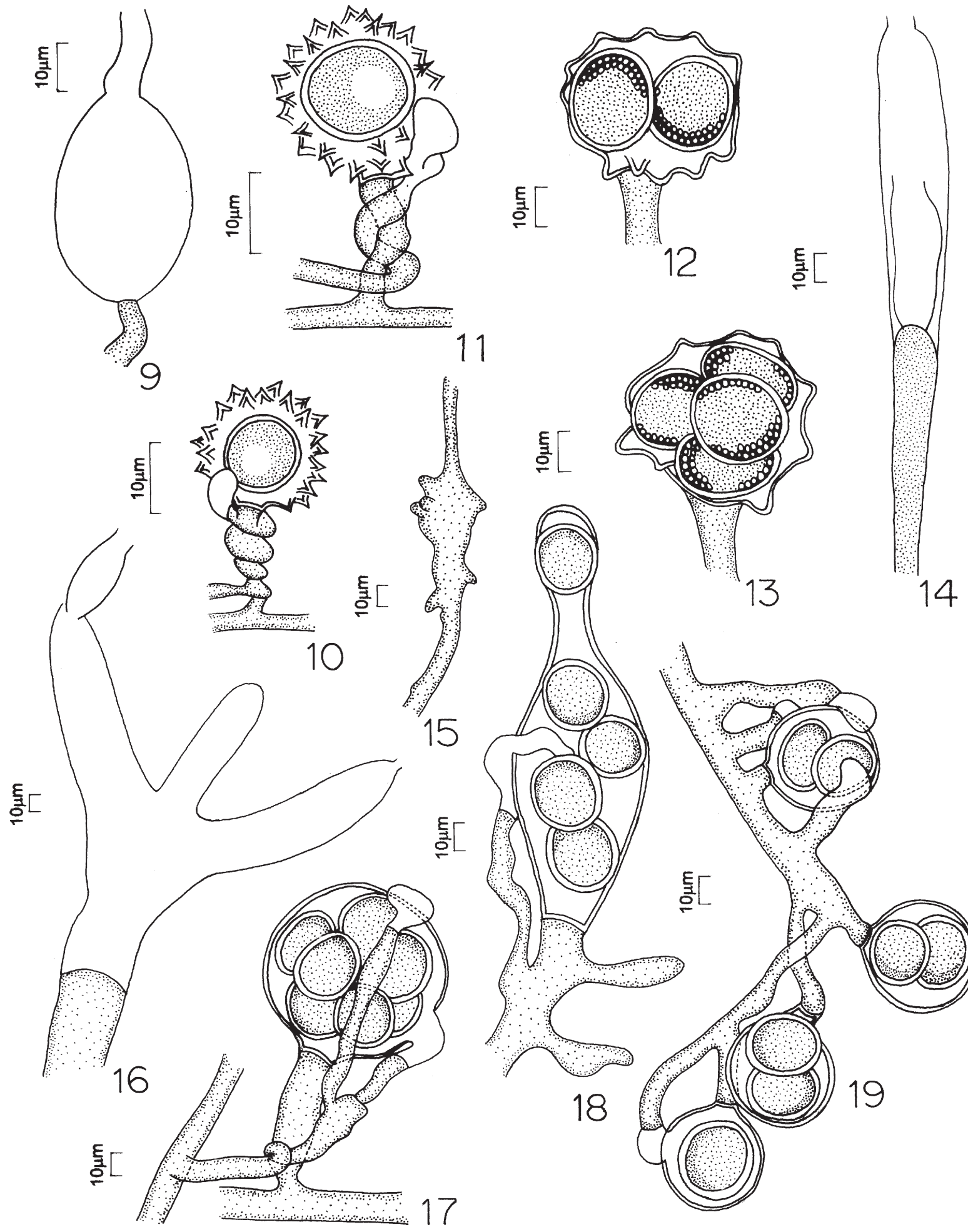

14

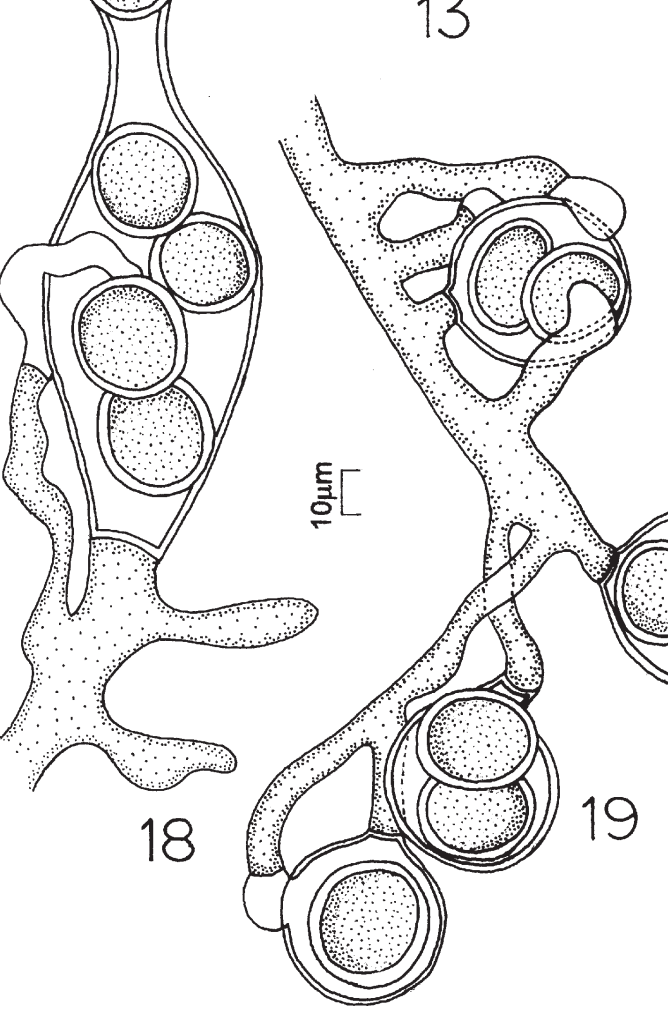

Figuras 9-19. Estruturas assexuais e sexuais. 9-11. Pythium helicandrum Drechsler. 9. Zoosporângio vazio. 10-11. Oogônios ornamentados com oósporos e anterídios díclinos. 12-15. Saprolegnia blelhamensis (Dick) Mil’ko. 12-13. Oogônios ornamentados com oósporos subcêntricos. 14. Zoosporângio com proliferação interna. 15. Gema. 16-19. S. terrestris Cookson ex Seymour. 16. Zoosporângio. 17-19. Oogônios com oósporos subcêntricos e anterídios díclinos e monóclinos.

Figures 9-19. Asexual and sexual structures. 9-11. Pythium helicandrum Drechsler. 9. Empty zoosporangium. 10-11. Ornamented oogonia with oospores and diclinous antheridia. 12-15. Saprolegnia blelhamensis (Dick) Mil'ko. 12-13. Ornamented oogonia and subccentric oospores. 14. Zoosporangia with internal proliferation. 15. Gemmae. 16-19. S. terrestris Cookson ex Seymour. 16. Zoosporangium. 17-19. Oogonia with subccentric oospores and diclinous and monoclinous antheridia. 


\section{Referências bibliográficas}

ALEXOPOULOS, C.J., MIMS, C.W. \& BLACKWELL, M. 1996. Introductory Mycology. $4^{\text {th }}$ ed., John Wiley \& Sons, New York.

ANTUNES, M.F.R., NINOMIYA, A. \& SCHOENLEINCRUSIUS, I.H. 1993. Efeitos da queimada sobre a micota de solo de Mata Atlântica na Reserva Biológica do Alto da Serra de Paranapiacaba, SP. Hoehnea 20:1-8.

COKER, W.C. \& MATTHEWS, V.D. 1937. North American Flora. The New York Botanical Garden, New York, v.2, part I, p.1-77.

COOKSON, I. 1937. Saprolegnia terrestris sp. nov., with some preliminary observations on Victorian soil Saprolegniales. Proceedings of the Royal Society of Victoria 49:235-242.

DICK, M.W. 1969. The Scoliolegnia asterophora aggregate, formerly Saprolegnia asterophora de Bary (Oomycetes). Botanical Journal of the Linnean Society 62:255-266.

DICK, M.W. 1973. Saprolegniales. In The fungi: an advanced treatise (G.C. Ainsworth, F.K. Sparrow \& A.S. Sussman, eds). Academic Press, New York, v.4B, p.113-144.

DRECHSLER, C. 1950. A Pythium with stout oogonial spines and coiled antheridial branches. Bulletin of the Torrey Botanical Club 77:442-461.

FIGUEIREDO, M.B. \& PIMENTEL, C.P.V. 1975. Métodos utilizados para conservação de fungos na Micoteca da Seção de Micologia Fitopatológica do Instituto Biológico. Summa Phytopathologica 1:299-302.

HARVEY, J.V. 1925. A study of the water molds and Pythiums ocurring in the soils of Chapel Hill. Journal of the Elisha Mitchell Scientific Society 41:151-164.

JOHNSON JUNIOR, T.W. 1956. The genus Achlya: morphology and taxonomy. University of Michigan Press, Ann Arbor, p.1-180.

JOHNSON JUNIOR, T.W., SEYMOUR, R.L. \& PADGETT, D.E. 2002. Biology and Systematics of the Saprolegniaceae. http://www.uncw.edu/people/padgett/book . (acesso em novembro/2002).

KARLING, J.S. 1987. Two new species of Leptolegniella and other zoosporic fungi in Thailand soils. Nova Hedwigia 45:433-443.

KIRK, P.M., CANNON, P.F., DAVID, J.C. \& STALPERS, J.A. 2001. Dictionary of Fungi. CABI Bioscience, Wallingford.
MILANEZ, A.I. 1989. Fungos de águas continentais. In Técnicas de coleta, preservação e herborização de material botânico (O. Fidalgo \& V.L. Bononi, coords.). Instituto de Botânica, São Paulo, p.17-20.

MILANEZ, A.I., PIRES-ZOTTARELLI, C.L.A. \& SCHOENLEIN-CRUSIUS, I.H. 1994. Fungos aquáticos da região de Mata Atlântica do Estado de São Paulo. In Anais do III Simpósio de Ecossistemas Brasileiros da Costa Brasileira (S. Watanabe, coord.). Aciesp, São Paulo, v.2, p.142-149.

PIRES-ZOTTARELLI, C.L.A. 1999. Fungos zoospóricos dos vales dos rios Moji e Pilões, região de Cubatão, São Paulo, SP. Tese de doutorado, Universidade Estadual Paulista, Rio Claro.

PIRES-ZOTTARELLI, C.L.A., SCHOENLEIN-CRUSIUS, I.H. \& MILANEZ, A.I. 1993. Quantitative estimation of zoosporic fungi and aquatic hyphomycetes on leaves submerged in a stream in the Atlantic Rainforest, in the State of São Paulo, Brazil. Revista de Microbiologia 24:192-197.

VAN DER PLAATS-NITERINK, A.J. 1981. Monograph of genus Pythium. Studies in Mycology 21:1-242.

ROGERS, A.L., MILANEZ, A.I. \& BENEKE, E.S. 1970. Additional aquatic fungi from São Paulo State. Rickia 5:93-110.

SCHOENLEIN-CRUSIUS, I.H. \& MILANEZ, A.I. 1998. Fungos zoospóricos (Mastigomycotina) da Mata Atlântica da Reserva Biológica do Alto da Serra de Paranapiacaba, Município de Santo André, SP. Revista Brasileira de Botânica 21:177-181.

SCHOENLEIN-CRUSIUS, I.H., PIRES-ZOTTARELLI, C.L.A. \& MILANEZ, A.I. 1992. Aquatic fungi in leaves submerged in a stream in the Atlantic Rainforest. Revista de Microbiologia 23:167-171.

SCHOENLEIN-CRUSIUS, I.H., PIRES-ZOTTARELLI, C.L.A. \& MILANEZ, A.I. 1999. Interaction between the mineral content and the occurrence number of aquatic fungi in leaves submerged in a stream in the Atlantic Rainforest, São Paulo, Brazil. Revista Brasileira de Botânica 22:133-139.

SECRETARIA DO MEIO AMBIENTE. 2000. Atlas das unidades de conservação ambiental do estado de São Paulo. Secretaria do Meio Ambiente, São Paulo.

SEYMOUR, R.L. 1970. The genus Saprolegnia. Nova Hedwigia 19:1-124.

SPARROW JUNIOR, F.K. 1960. Aquatic Phycomycetes. $2^{\text {nd }}$ ed. University of Michigan Press, Ann Arbor. 